nhân thu thâp còn ít, bước đầu so sánh các đặc điểm sinh học và nhận thấy một số khác biệt có ý nghĩa, chưa đánh giá kết quả điều trị cũng như theo dôi thời gian sống còn của bệnh nhân trước khi kết luận nhóm có khuếch đại 1q là xấu so với nhóm không có khuếch đại 1q.

\section{KẾT LUÂ̂N}

Trong nghiên cứu này, chúng tôi đã mô tả các đặc điểm lâm sàng và cận lâm sàng của bệnh nhân đa u tủy mới chẩn đoán có khuếch đại NST 1q, và cho thây có sự khác biệt so với nhóm không có khuếch đại NST' 1q.

\section{TÀI LIÊU THAM KHẢO}

1. Chen D., Zhou D., Xu J., et al. (2019), "Prognostic Value of 1q21 Gain in Multiple Myeloma", Clin Lymphoma Myeloma Leuk, 19 (3), pp. e159-e164.

2. Bladé J., de Larrea C. F., Rosiñol L. (2012), "Extramedullary involvement in multiple myeloma", Haematologica, 97 (11), pp. 1618.
3. Fabris S., Ronchetti D., Agnelli L., et al. (2007), "Transcriptional features of multiple myeloma patients with chromosome 1q gain", Leukemia, 21 (5), pp. 1113-1116.

4. Grzasko N., Hajek R., Hus M., et al. (2017), "Chromosome 1 amplification has similar prognostic value to del $(17 \mathrm{p} 13)$ and $\mathrm{t}(4 ; 14)(\mathrm{p} 16$; q32) in multiple myeloma patients: analysis of reallife data from the Polish Myeloma Study Group", Leukemia \& lymphoma, 58 (9), pp. 2089-2100.

5. Karim K. J., Hassan A. M., Getta H. A., et al. (2020), "Frequency and prognostic significance of hypercalcemia in patients with multiple myeloma", Medical Journal of Babylon, 17 (4), pp. 327.

6. Kenneth Kaushansky M., MACP, Marshall A. Lichtman M., Josef T. Prchal $M_{\text {., }}$ et al. (2016), "Williams Hematology 9th", Part XI (107), pp. 1733 - 1747.

7. Kyle R. A., Gertz M. A., Witzig T. E., et al., "Review of 1027 patients with newly diagnosed multiple myeloma". in Mayo Clinic Proceedings. 2003. Elsevier.

8. Rossi D., Fangazio M., De Paoli $L_{\text {., }}$ et al. (2010), "Beta-2-microglobulin is an independent predictor of progression in asymptomatic multiple myeloma", Cancer, 116 (9), pp. 2188-2200.

\title{
ĐẶC ĐIỂM XƯƠNG HÀM DƯỚI TRÊN PHIM SỌ NGHIÊNG TELE TỪ XA (CEPHALOMETRICS) Ở BÊ̂NH NHÂN SAI LỆCH XƯƠNG LOẠI III
}

\section{TÓM TẮT}

Sai lệch xương loại III được coi là môt rối loạn phức hợp so - mặt phức tạp, có thể là biểu hiện sứ nhô ra của hàm dưới hoặc hàm trên lùi sau hoặc kết hợp cả hai. Sự hiểu biết về đăc điểm tăng trưởng so mặt, đặc biệt cấu trúc xương hàm dưới ở nhóm bệnh nhân này sẽ giúp bác sĩ xác đinh được thời gian và cơ học điều trị. Nghiên cứu nhẳm mục đích mô tả đặc điểm xương hàm dưới trên phim Cephalometrics ở bệnh nhân sai lệch xương loại III tại Viện Đào tạo Rằng Hàm Măt - Trường Đai họ Y Hà Nội. Phim so nghiêng từ xa trước điều trị của 70 bệnh nhân từ 18 tuổi trở lên, không có tiền sử chấn thương hoặc dị tật vùng hàm mặt, được đo đạc, phân tích và chia thành các nhóm kiểu mặt ngắn, trung bình, dài. Kết quả: trong các nguyên nhân gây sai lệch xương loại III, nguyên nhân do quá phát xương hàm dưới chiếm $55.72 \%$, tiếp đến là nguyên nhân do kém phát triển xương hàm trên và với $17.14 \%$ là do kết hợp kém phát triển xương hàm trên và quá phát xương hàm dưới. Trong số bệnh nhân tham gia nghiên cứu , 37 người có kiểu mă̆t trung bình, 19 bênh nhân có kiểu mặt ngắn và bệnh nhân có kiểu mặt dài là 14 người.

*Trường Đại học Y Hà Nội

Chịu trách nhiệm chính: Trần Thị Diệu Linh

Email: dieulinhrhm@gmail.com

Ngày nhận bài: 3.6.2021

Ngày phản biên khoa họ: 3.8.2021

Ngày duyệt bài: 11.8.2021

\section{Trần Thị Diệu Linh*, Quách Thị Thúy Lan*}

Các đặc điểm về chiều dài cành cao, chiều dài nền xương và chiều dài Co-Gn ở nhóm bênh nhân nam lớn hơn giá trị tương ứng ở nhóm nữ giới.

Tư khóa: xương hàm dưới, sai lệch xương loại III, phim sọ nghiêng, Trường Đại học Y Hà Nội.

\section{SUMMARY \\ THE CHARACTERISTICS OF THE MANDIBLE ON LATERAL TELETOLOGICAL CEPHALOMETRIC FILM IN PATIENTS WITH CLASS III MALOCCLUSION}

Class III malocclusion is considered a complex cranio-facial disorder, which may represent mandibular prognathism or maxillary retrognathism, or a combination of both. Understanding the characteristics of cranio-facial growth, especially mandibular structures in this group of patients will help doctors determine the timing and mechanics of treatment. The study aimed to describe the characteristics of the mandibule on Cephalometrics films in patients with class III malocclusion at the Institute of Odonto-Stomatology - Hanoi Medical University. Pretreatment lateral cephalometric radiographs of 70 patients with 18 years or older, with no history of trauma or craniofacial anomalies, were measured, analyzed and classified into short, average, and long faces. Results: in the different combinations between maxillomandibular relationships in the class III group, prognathic mandible is accounted for $55.72 \%$, followed by the retrognathic maxilla and the $17.14 \%$ is due to a combination of both. Among the 
patients participating in the study, 37 patients have average face, 19 patients with short face and 14 patients with long face. The characteristics of ramus height, mandibular body length and mandibular unit length of the male subjects are higher than the corresponding values of the female subject group.

Keywords: mandible, class III malocclusion, lateral cephalometric, Hanoi Medical University.

\section{I. ĐẶT VẤN ĐỀ}

Xương hàm dưới là xương có vận động linh hoạt, có nhiều đường cong theo các hướng khác nhau như cằm và góc hàm, góp phần quan trọng tạo nên các đường nét đặc trưng của từng chủng tộc cũng như của mỗi giới. Sự tăng trưởng, phát triển và đặc biệt kiểu xoay của xương hàm dưới khi tăng trưởng ảnh hưởng rõ đến cường độ mọc răng, hướng mọc răng cũng như vị trí trước sau của các răng trên cung hàm, đặc biệt là nhóm răng cửa. ${ }^{2}$ Điều đó có thể góp phần làm khởi phát hoặc làm trầm trọng thêm tình trạng sai lệch khớp cắn của bệnh nhân.

Sai lệch xương loại III được coi là một rối loạn phức hợp sọ - mặt phức tạp, có thể là biểu hiện sự nhô ra của hàm dưới hoặc hàm trên lùi sau hoặc kết hợp cả hai. Tỷ lệ sai lệch xương loại III là khác nhau giữa các chủng tộc và ngày càng phổ biến ở người châu Á. Yang đã phát hiện rằng $40 \%$ - 50\% bệnh nhân chỉnh nha tại Hàn Quốc tìm tới bác sĩ với sai lệch xương loại III. ${ }^{4}$

Đô nghiêng của mặt phẳng hàm dưới (MP$\mathrm{SN}$ ) là một yếu tố chính quyết định kích thước dọc của khuôn mặt (dài hay ngắn). Một người có góc MP-SN lớn thường có kiểu mặt dài và người có góc MP-SN nhỏ thường có kiểu mặt ngắn. Các sai lệch xương loại III được phân loại dựa theo góc này thấp hay cao (xoay trước hoặc sau) hoăcc các kiểu cắn sâu và hở.

Ở Việt Nam, đã có nhiều nghiên cứu, đánh giá, phân tích cấu trúc sọ mặt trên phim đo sọ nghiêng đối với từng loại sai lệch xương, nhưng nghiên cứu đánh giá riêng đặc điểm xương hàm dưới trên phim đo so nghiêng thì chưa nhiều. Vì vậy, chúng tôi tiến hành nghiên cứu: "Đặc điểm xương hàm dưới trên phim so nghiêng tele từ xa (Cephalometrics) ở bệnh nhân sai lệch xương loại III" với mục tiêu: Mô tả đặc điểm xương hàm dưới trên phim Cephalometrics ở bệnh nhân

\section{KẾT QUẢ NGHIÊN CỨU}

\subsection{Phân loại nguyên nhân gây sai lệch xương loại III}

\begin{tabular}{|c|c|c|c|c|c|c|c|}
\hline & \multicolumn{2}{|c|}{ Tống(n=70) } & \multicolumn{2}{c|}{ Nam (n= 27) } & \multicolumn{2}{c|}{ Nữ (n= 43) } & \multirow{2}{*}{ P } \\
\cline { 2 - 7 } & $\mathbf{n}$ & $\mathbf{\%}$ & $\mathbf{n}$ & $\mathbf{\%}$ & $\mathbf{n}$ & $\mathbf{\%}$ & \\
\hline Nhóm A & 39 & 55,72 & 16 & 59,26 & 23 & 53,49 & \multirow{2}{*}{$0.1^{*}$} \\
\hline Nhóm B & 19 & 27,14 & 4 & 14,81 & 15 & 34,88 & 11,63 \\
\hline Nhóm C & 12 & 17,14 & 7 & 25,93 & 5 & \\
\hline
\end{tabular}

sai lệch xương loại III tại Viện Đào tạo Răng Hàm Mặt - Trường Đại học Y Hà Nội.

2.1. Đối tượng nghiên cứu: 70 bệnh nhân đến khám và được chẩn đoán có sai lệch xương loại III, có chỉ định chụp phim sọ nghiêng từ xa tại Viện Đào tạo Răng Hàm Mặt - Trường Đại học Y Hà Nội. Sai lệch xương loại III do các nguyển nhân: nhóm $A$ (quá phát xương hàm dưới), nhóm $B$ (kém phát triển xương hàm trên), nhóm $C$ (kết hợp kém phát triển xương hàm trên và quá phát xương hàm dưới).

- Tiêu chuẩn lựa chọn:

- Độ tuổi: từ 18 tuổi trở lên.

- Bệnh nhân có đủ số lượng 28 răng trên cung hàm (không kể răng số 8).

- Chưa có tiền sử điêuu trị chỉnh hình hoặc phục hình trước đó.

- Trên phim so nghiêng, bệnh nhân được phân loại sai lệch loại III do xương: dựa vào số đo góc ANB: Loaii III: góc ANB < $0^{\circ}$

\section{Tiêu chuẩn loại trứ:}

- Bệnh nhân có tiền sử chấn thương hàm mặt hoặc dị tật vùng hàm mặt (hở môi hoặc vòm miểng, hội chứng sọ mặt) làm ảnh hưởng đến sự phát triển của khối sọ mặt.

- Tiêu chuẩn loại trừ phim:

- Phim quá sáng hoăc tối

- Không nhìn rõ các cấu trúc mô xương và mô mềm

- Đối tượng nghiêng đầu quá mức hoặc không cắn khít

○ Khớp cắn hai bên không trùng nhau.

2.2. Phương pháp nghiên cứu: Nghiên cứu mô tả cắt ngang. Phim sọ nghiêng của bệnh nhân được chia thành các nhóm kiểu mă̆t ngắn, dài, trung bình, sau đó vẽ, đo đạc các biến số về đặc điểm xương hàm dưới.

Góc mặt phẳng hàm dưới - nền sọ: góc tạo bởi mặt phẳng hàm dưới (đường thẳng qua Go$\mathrm{Gn}$ ) và mặt phẳng nền sọ (đường thẳng qua $\mathrm{S}$ $\mathrm{N})$. Đánh giá kiểu mặt theo chiêu đứng:

+ Kiểu mặt ngắn: góc $\mathrm{SN}-\mathrm{GoGn}<28^{\circ}$.

+ Kiểu mặt trung bình: góc $S N-G o G n=32^{\circ} \pm 4^{\circ}$ + Kiểu mặt dài: góc $S N-G o G n>36^{\circ}$

2.3. Xử lý số liệu: số liệu được nhập và xử lý bằng phần mềm SPSS 16.0

\section{II. ĐỐI TƯƠNGG VÀ PHƯƠNG PHÁP NGHIÊN CỨU}


Nhận xét: Trong số 70 đối tượng nghiên cứu, đa số đối tượng nghiên cứu bị sai lệch xương hạng III nhóm A (do quá phát xương hàm dưới) chiếm $55,72 \%$. Và ít nhất là có 12 đối tượng có sai lệch xương nhóm $C$ (do cả quá phát xương hàm dưới và kém phát triển xương hàm trên) chiếm 17,14\%. Trong sỗ các bệnh nhân là nữ giới, sự phân bố nguyên nhân gây sai lệch xương cũng tương tự. Đối với các bệnh nhân nam giới thì gặp ít nhất là nhóm do kém phát triển xương hàm trên (chiếm 14,81\%). Tuy nhiên, sự khác biệt giữa hai giới là không có ý nghĩa thống kê trong nghiên cứu của chúng tôi. (kiếm định $X^{2}$ )

3.2. Phân bố các kiểu mặt của bệnh nhân sai lệch xương loại III

\begin{tabular}{|c|c|c|c|c|c|c|c|}
\hline \multirow{2}{*}{ Kiểu mặt } & \multicolumn{2}{|c|}{ Tống $(n=70)$} & \multicolumn{2}{|c|}{$\operatorname{Nam}(n=27)$} & \multicolumn{2}{|c|}{ Nũ̃(n=43) } & \multirow[b]{2}{*}{$\mathbf{P}$} \\
\hline & $\mathbf{n}$ & $\%$ & $\mathbf{n}$ & $\%$ & $\mathbf{n}$ & $\%$ & \\
\hline Dài & 14 & 20 & 6 & 22,22 & 8 & 18,6 & \\
\hline Trung bình & 37 & 52,86 & 12 & 33,33 & 25 & 23,26 & $0,52^{*}$ \\
\hline Ngắn & 19 & 27,14 & 9 & 44,44 & 10 & 58,14 & \\
\hline
\end{tabular}

Nhận xét: Trong nghiên cứu của chúng tôi, kiếu mặt trung bình là gặp nhiều nhất ở bệnh nhân sai lệch xương loại III chiếm $52,86 \%$ và ít nhất là kiểu mặt dài (14/70 bệnh nhân). Sự phân bố kiểu mă̆t cũng tương tự ở từng nhóm nam và nữ. Tuy nhiên sự khác biệt giữa hai giới không có ý nghĩa thống kê. (kiếm định $x^{2}$ )

3.3. Một số đặc điểm xương hàm dưới của đôii tượng nghiên cứu

\begin{tabular}{|c|c|c|c|c|}
\hline & Tống (M $\pm s d)$ & Nam (M士 sdo & $N \tilde{u}(M \pm s d)$ & $\mathbf{p}$ \\
\hline SN-GoGn & $30,81 \pm 6,49$ & $30,47 \pm 8,07$ & $31,02 \pm 5,36$ & $0,73^{*}$ \\
\hline Ar-Go-Me & $122,43 \pm 12,35$ & $112,09 \pm 17,47$ & $122,64 \pm 7,83$ & $0,47 * *$ \\
\hline SNB & $84,9 \pm 4,99$ & $85,81 \pm 5,72$ & $85,32 \pm 4,44$ & $0,12 * *$ \\
\hline Pog - N-perp(FH) (mm) & $4,6 \pm 7,69$ & $6,15 \pm 8$ & $3,62 \pm 7,41$ & $0,18^{*}$ \\
\hline Cành cao $(\mathrm{mm})$ & $47,22 \pm 5,34$ & $49,26 \pm 6,16$ & $45,94 \pm 4,39$ & $0,01 * *$ \\
\hline Chiều dài nền(mm) & $76,18 \pm 5,11$ & $78,8 \pm 5$ & $74,54 \pm 4,5$ & $<0,001^{*}$ \\
\hline Chiều dài Co-Gn (mm) & $116,76 \pm 8$ & $121,68 \pm 8,07$ & $113,66 \pm 6,27$ & $<0,001 *$ \\
\hline IMPA & $85,79 \pm 12,07$ & $82,59 \pm 14,9$ & $87,79 \pm 9,55$ & $0,17^{* *}$ \\
\hline $1 \mathrm{~L} / \mathrm{NB}$ & $23,38 \pm 7,79$ & $21,28 \pm 7,98$ & $24,7 \pm 7,47$ & $0,07 *$ \\
\hline Kc $1 \mathrm{~L} / \mathrm{NB}$ & $4,66 \pm 3,32$ & $3,82 \pm 2,61$ & $5,18 \pm 3,62$ & $0,37^{* *}$ \\
\hline
\end{tabular}

*: Kiểm định t- test độc lập, **: Kiếm định Mann Whitney test

Nhân xét: Tương quan theo chiều đứng, giá trị góc SN-GoGn và góc Ar-Go-Me trong giới hạn bình thường. Tương quan theo chiều trước sau, góc SNB và khoảng cách Pog- mặt phẳng qua $\mathrm{N}$ vuông góc $\mathrm{FH}$ đều lớn hơn giá trị trung bình, cho thấy xương hàm dưới so với nền so có chiều đứng bình thường nhưng vị trí ở phía trước, cằm đưa ra trước. Tuy nhiên, các giá trị này ở giới nam và nữ lai như nhau.

Đánh giá hình thái xương hàm dưới trong nghiên cứu thấy: chiều dài cành cao, chiều dài nền xương hàm dưới đều lớn hơn giá trị bình thường, chứng tỏ kích thước xương hàm dưới ở bệnh nhân trong nghiên cứu dài hơn bình thường. Ngoài ra, có sự khác biệt có ý nghĩa thống kê của các chỉ số này ở từng giới. Cụ thể, các bệnh nhân nam có giá trị lớn hơn giá trị tương ứng ở nhóm bênh nhân nữ.

Đánh giá đặc điểm răng cửa hàm dưới, góc IMPA và góc giữa trục răng cửa dưới - đường NB nhỏ hơn giá trị trung bình, cho thấy trục răng cửa dưới ngả về phía lưỡi. Các giá trị này là tương tự nhau ở hai giới nam và nữ.

\section{BÀN LUẬN}

4.1. Phân loại nguyên nhân gây sai lệch xương loại III. Trong nghiên cứu của chúng tôi, nguyên nhân do quá phát xương hàm dưới là nhiêu nhất chiếm $55.72 \%$, và ít nhất với $12 / 70$ bệnh nhân là do kết hợp kém phát triển xương hàm trên và quá phát xương hàm dưới.

Kết quả này cũng tương tư nghiên cứu của Nguyễn Hồng Thủy, trong 51 bệnh nhân sai lệch loại III do xương thì chiếm tỉ lệ nhiều nhất là do nguyên nhân hàm dưới (31/51 bênh nhân tức $60.8 \%$ ), sau đó là do nguyên nhân hàm trên và ít nhất cũng là do kết hợp cả xương hàm trên và xương hàm dưới (4/51 bệnh nhân). ${ }^{3}$

Trong nghiên cứu của Marcus $B$. Vasconcelos và cộng sự năm 2014, với cùng cách thức phân loại các nguyên nhân gây sai lệch xương loại III, trong 37 bệnh nhân thì có 25 người do quá phát xương hàm dưới chiếm tỉ lệ cao nhất $(67.6 \%)$, sau đó là 7 bệnh nhân bị sai lệch do xương hàm trên kém phát triển và thấp nhất là có 5 bệnh nhân đến khám do nguyên nhân ở cả hai hàm. ${ }^{5}$

\subsection{Phân bố các kiểu mặt của bênh}


nhân sai lệch xương loại III. Góc mặt phẳng hàm dưới là một trong các chỉ số đánh giá chiều cao tâng mặt dưới và xu hướng phát triển theo chiều đứng của xương hàm dưới. Đặc biệt, khi điều trị những ảnh hưởng do sai lệch xương loại III, tùy giai đoạn phát triển của bệnh nhân và tùy vào góc mặt phẳng hàm dưới mà bác sĩ lựa chọ kế hoach điều trị khác nhau.

Khi phân loại bệnh nhân sai lệch xương loại III dựa vào góc mặt phẳng hàm dưới, 37 bệnh nhân có kiểu mặt trung bình, chiếm đa số, 19/70 bênh nhân có kiểu mặt ngắn và ít nhất là bênh nhân có kiểu mặt dài chiếm $20 \%$. Kiểu mặt ngắn và kiểu mặt trung bình sẽ thuận lợi hơn khi sử dụng các khí cụ ngoài mặt như facemask, chincup...để giới hạn sự phát triển xương hàm dưới khi nguyên nhẩn gây lệch lạc xương bắt nguồn từ xương hàm dưới.

Trong nghiên cứu của Núria Molina-Berlanga và cộng sự năm 2013, trong 62 bệnh nhân sai lệch xương loại III mà tác giả đo đạc, kiểu mặt ngắn là nhiều nhất với 26/62 bệnh nhân, tiếp đến là kiểu mặt dài (19/62 bệnh nhân) và ít nhất là kiểu mặt trung bình (17/62 bệnh nhân). ${ }^{6}$ Sư khác biệt so với nghiên cứu của chúng tôi có thể do đối tượng nghiên cứu của tác giả là những người da trắng trưởng thành. Ngoài ra, tiêu chí phân loai kiểu mắt dài của tác giả là góc SNGoGn $>35^{\circ}$, mặt trung bình là góc từ $30-35^{\circ}$ và mặt ngắn khi góc $<29^{\circ}$.

4.3. Một số đặc điểm xương hàm dưới của đối tượng nghiên cứu. Xương hàm dưới có vị trí và vai trò quan trọng trong việc chẩn đoán và lên kế hoạch điều trị các trường hợp sai lệch xương loại III. Một số đặc điểm của xương hàm là có thể đo được trên phim cephalometrics.

Để xét tương quan theo chiều trước - sau, góc SNB trung bình $84,9^{\circ}$ và khoảng cách trung bình từ Pog đến mặt phẳng qua $\mathrm{N}$ vuông góc $\mathrm{FH}$ là $4,6 \mathrm{~mm}$. Roodabeh Koodaryan và cộng sự khi phân tích phim sọ nghiêng của 50 bệnh nhân sai lệch loại III thu được giá trị góc SNB là $82,17^{\circ} \pm$ 3,350 và khoảng cách từ điểm Pog dao động $1,12 \pm 6,15 \mathrm{~mm} .^{7}$ Mặc dù đều nghiên cứu trên độ tuổi trưởng thành nhưng tiêu chuẩn xếp loại sai lệch loại III của Roodabeh là tương quan răng hàm lớn thứ nhất hạng III ở vị trí tương quan tâm, mặt lõm và cắn chìa âm. Do đó, thu được kết quả có sự khác biệt với nghiên cứu của chúng tôi.

Mặt khác, trong các chỉ số phản ánh đặc điểm hình thái xương hàm dưới, chỉ số chiều dài CoGn xương hàm dưới thu được trong khoảng $116,76 \pm 8 \mathrm{~mm}$. Nghiên cứu của Roodabeh thì công bố chỉ số Co-Gn là 130,14 $\pm 7,804 \mathrm{~mm}$ của 50 bệnh nhân ở thành phố Tabriz, Iran - một đất nước vùng Trung Á chứ không giống ở Việt Nam. Kết quả chúng tôi thu được gần giống kết quả trong nghiên cứu của Trương Thị Mai Anh, cụ thể là ở nam giá trị này lớn hớn nữ, ở nam giới là $118,07 \pm 9,57 \mathrm{~mm}$ và ở nữ là $111,71 \pm 9,12 \mathrm{~mm}$. $^{8}$

Đặc điểm răng cửa hàm dưới cũng là một điểm cần lưu ý khi điều trị các bệnh nhân sai lệch xương loại III. Đặc điểm trục rằng cửa hàm dưới với mặt phẳng Go-Me có kết quả 85,79 \pm $12,07^{\circ}$. Núria Molina-Berlanga lại công bố giá trị IMPA là $81,4 \pm 7,8^{\circ}$, khoảng giá trị thu hẹp hơn so với kết quả chúng tôi thu được, có thể là do ngoài tiêu chí góc $A N B<0^{\circ}$ thì Núria Molina còn bổ sung thêm chỉ số Wits $\leq-1 \mathrm{~mm}$ để lựa chon bệnh nhân có bất thường xương loại III. ${ }^{6}$ Khi đánh giá trục răng cửa hàm dưới với mặt phẳng NB thì chúng tôi thu được góc L1/NB là 23,38 \pm $7,79^{\circ}$ và khoảng cách L1-NB là $4,66 \pm 3,32 \mathrm{~mm}$; còn Nguyễn Hồng Thủy công bố L1/NB là 26,53 $\pm 7,56^{\circ}$ và $L 1-N B$ là $6,10 \pm 2,65 \mathrm{~mm}$. Nguyễn Hồng Thủy và cộng sự không căn cứ vào tương quan xương mà lại lấy tương quan răng hàm lớn thứ nhất ở hạng III để lựa chọn đối tượng nghiên cứu là bệnh nhân bị sai lệch khớp cắn loại III, bao gồm cả những bệnh nhân có vấn đề về phần xương và cả những bệnh nhân có vấn đề do răng. ${ }^{3}$

\section{KẾT LUẬN}

- Nguyên nhân do quá phát xương hàm dưới là nhiều nhất, tiếp đến là nguyên nhân do kém phát triển xương hàm trên và ít nhất là do kết hợp kém phát triển xương hàm trên và quá phát xương hàm dưới. Sự khác biệt không có ý nghĩa thống kê về nguyên nhân gây sai lệch giữa hai giới.

- Trong số các bệnh nhân có sai lệch xương loại III tham gia nghiên cứu, đa số là kiểu mặt trung bình, kiểu mặt dài gặp ít nhất, sự phân bố các loại kiểu mặt là như nhau giữa bệnh nhân nam và nữ.

- Các đặc điểm về góc Gonial (Ar-Go-Me), góc SNB, góc mặt phẳng hàm dưới và đặc điểm răng cửa hàm dưới là giống nhau ở cả nam và nữ. Tuy nhiên, chiều dài cành cao, chiều dài nền xương cũng như chiều dài Co-Gn ở bệnh nhân nam giới lại lớn hơn so với ở nữ giới.

\section{TÀI LIÊU THAM KHẢO}

1. Anh Trương Thị Mai, Đặc điểm hình thái nền sọ xương hàm trên, xương hàm dưới trên phim sọ mặt nghiêng của bệnh nhân sai khớp cắn loại III xương, Luận văn tốt nghiệp Bác sĩ nội trú, Trường Đại học Y Hà Nội, 2016, 44. 
2. Đại học Y Dược Thành phố Hồ Chí Minh, Chỉnh hình răng măt, Nhà xuất bản $Y$ hoc, 2004, 32.

3. Thủy Nguyến Hồng, Một số chî số sọ - mặt trên phim sọ nghiêng từ xa kỹ thuật số ở người Việt độ tuổi 18 - 25 sai khớp cắn loại III theo Angle, Luận văn Thạc sĩ Y học, Trường Đại học Y Hà Nội, 2017, $37-41$.

4. Fengshan Chen, LiPing Wu et al, Longitudinal Intermaxillary Relationships in Class III Malocclusions with Low and High Mandibular Plane Angles, Angle Orthodontist, 2007, 77 (3), 397-403.

5. Marcus Barreto Vasconcelos, Célia Regina M.P.Vercelino et al, Cephalometric characteristics of Class III malocclusion In Brazilian individuals, The Brazilian Journal of Oral Sciences, 2014, 13 (4), 314 - 318.

6. Nu' ria Molina-Berlanga, Jaume LlopisPerez et al, Lower incisor dentoalveolar compensation and symphysis dimensions among Class I and III malocclusion patients with different facial vertical skeletal patterns, Angle Orthodontis, 2013, 83 (6), 948 - 955.

7. Roodabeh Koodaryan, Ali Rafighi et al, Components of Adult Class III Malocclusion in an Iranian Population, Journal of Dental Research Dental Clinics Dental Prospects, 2009, 3 (1), 20 - 23.

\section{PHÂN TÍCH NGƯỡ'NG CHI TRẢ TRÊN MỖI NĂM SỐNG CÓ CHẤT LƯỢNG TĂNG THÊM CỦA NGƯỜI BỆNH HEN PHẾ QUẢN TẠI BỆNH VIỆN QUẬN 11}

\section{TÓM TẮT}

Hen phế quản là một trong những bệnh gây gánh nặng về bệnh tật và kinh tế tương đối lớn cho các quốc gia. Ngưỡng chi trả của người bệnh trong điều tri bệnh hen phế quản là chỉ số quan trọng đánh giá khả nẳng tiếp cận của người bệnh và là cở sở lựa chọn liệu pháp điều trị phù hợp cũng như cơ sở xây dưng các chính sách y tế hợp lý cho người bệnh hen phế quản. Nghiên cứu được thực hiện tại bệnh viện Quận 11 trên mâuu nghiên cứu gồm 137 người bệnh hen phế quản, tỉ

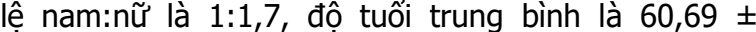
14,$31 ; 35,8 \%$ người bệnh là nội trợ và chưa có việc làm; $99,3 \%$ sinh sông ở thành thị; thu nhâp trung bình/tháng có giá trị 3.548.175 \pm 3.428 .901 VNĐ; thời gian phát hiện bệnh trung bình $5,23 \pm 0,14$ năm. Nghiên cứu ghi nhận hệ số chất lượng sống liên quan đến sức khỏe dựa trên thang đo EQ-5D-5L có giá trị trung bình $0,816 \pm 0,013$, ngưỡng chi trả trên một năm sống có chất lượng (WTP/QALY) có giá trị trung bình 89.828.747 \pm 11.497.859 VNĐ/QALY. Các yếu tố liên quan đến WTP/QALY bao gồm chất lượng sống liên quan đến sức khỏe, nghề nghiệp, trình độ học vấn, mức thu nhập, bệnh kèm và giai đoạn bệnh. WTP/QALY đóng vai trò quan trọng trong việc đưa ra các quyết định phân bổ nguồn lực y tế.

Tư khóa: Ngưỡng chi trả cho một năm sống có chất lượng, hen phế quản, bệnh viện quận 11.

\section{SUMMARY \\ WILLINGNESS-TO-PAY PER QUALITY- ADJUSTED LIFE YEAR OF PATIENTS WITH}

${ }^{1}$ Đại học Y Dược Thành phố Hồ Chí Minh

${ }^{2}$ Đại học Nguyễn Tất Thành

${ }^{3}$ Bệnh viện Quận 11, Thành phố Hồ Chí Minh

Chịu trách nhiệm chính: Nguyễn Thị Thu Thủy

Email: nguyenthuthuy@ump.edu.vn

Ngày nhận bài: 1.6.2021

Ngày phản biên khoa hoc: 2.8.2021

Ngày duyệt bài: 10.8 .2021

\section{Hồ Thị Minh Anh ${ }^{1}$, Nguyễn Thị Xuân Liễu ${ }^{2}$, Phạm Anh Tuấn ${ }^{3}$, Nguyễn Thị Thu Thủy ${ }^{1}$}

\section{ASTHMA IN DISTRICT 11 HOSPITAL}

Asthma is one of the diseases causing a relatively huge economic and disease burden for many countries. Considering the willingness to pay in the treatment of asthma as well as the ability to access treatment methods is necessary to choose the right treatment therapy, and to form the basis for building policies to support asthma patients. The study was conducted at District 11 hospital in HCMC included 137 patients with asthma with male:female ratio of $1: 1.7$, the average age of $60.69 \pm 14.31,35.8 \%$ housewives and unemployed; $99.3 \%$ living in urban areas; the average monthly income of 3,548,175 $\pm 3,428,901$ VND and the mean duration of the disease of $5.23 \pm$ 0.14 years. This study recorded that the mean healthrelated quality of life was $0.816 \pm 0.013$ based on EQ$5 \mathrm{D}-5 \mathrm{~L}$, the average value of willingness to pay per quality-adjusted life-year (WTP/QALY) was $89,828,747$ $\pm 11,497,859$ VND. Influential factors to WTP/QALY included health-related quality of patients' life, occupation, education level, income level, comorbidities, and disease stage. The WTP/QALY plays an important role in making decision for healthcare resource allocations.

Keywords: Willingness to pay, asthma, District 11 hospital

\section{I. ĐĂT VẤN ĐỀ}

Trong các bệnh lý không lây nhiễm, hen phế quản (HPQ) được coi là bệnh lý mang tính toàn câu. Với tỉ lệ mắc bệnh $\mathrm{HPQ}$ ngày càng gia tăng ở các nước với đủ mọi lứa tuổi, tổ chức Y tế Thế giới (World Health Organization - WHO) ước tính có khoảng 300 triệu người mắc $\mathrm{HPQ}$ năm 2005 và dự đoán sẽ tăng lên khoảng 400 triệu người vào năm 2025 [1]. Là một đất nước nhiệt đới, tî lệ người bệnh (NB) HPQ quanh năm ở Việt Nam khá cao. Tại Việt Nam, theo điều tra của Hội Hen - Dị ứng - Miễn dịch lâm sàng, trung bình có $5 \%$ 